\title{
A TRADUÇÃO COMO POTÊNCIA PARA A TRADIÇÃO LITERÁRIA
}

\section{TRANSLATION AS A FORCE IN LITERARY TRADITIONS \\ Karina de Castilhos Lucena*}

\section{RESUMO}

Este texto expõe alguns cruzamentos entre tradução e tradição literária, mais precisamente o papel que a literatura traduzida pode desempenhar na formação de sistemas literários nacionais/regionais. A reflexão está estruturada em duas partes: na primeira, comento os estudos de Itamar Even-Zohar (1939), Franco Moretti (1950) e especialmente Ricardo Piglia $(1940$ - 2017), três autores que identificaram a tradução como potência para a tradição literária. Depois, apresento brevemente as trajetórias intelectuais de Roberto Arlt (1900 1942) e Juan Carlos Onetti (1909 - 1994), demonstrando que esses escritores dependeram da tradução para acessarem a cultura letrada.

Palavras-chave: Tradução; Tradição literária; literatura hispano-americana.

\section{ABSTRACT}

This text examines some of the exchanges between translation and literary traditions, specifically the role that translated literature may play in the formation of national or regional literary systems. The first part discusses the work of three authors who have identified translation as a force in literary traditions: Itamar Even-Zohar (1939), Franco Moretti (1950), and especially Ricardo Piglia (1940-2017). The second outlines the intellectual trajectories of Roberto Arlt (1900-1942) and Juan Carlos Onetti (1909-1994), demonstrating the extent to which these writers relied on translations in order to have access to literary culture.

Keywords: translation; literary traditions; hispanic american literature.

Respiração artificial (1980), o canônico romance-ensaio de Ricardo Piglia (Buenos Aires, 1940 - 2017), trata da história política argentina, da história da literatura argentina, da história familiar do narrador. Esses três vetores já seriam matéria suficiente para a narração - e a conexão entre eles, ligados entre si como a aparelhos que possibilitam a respiração, garante a qualidade superior do romance; mas o escritor propõe mais. Acrescenta um quarto debate ainda hoje secundarizado em relação aos anteriores: o papel determinante que a tradução pode assumir na tradição literária local. Em Respiração artificial, a tradução aparece em dois momentos. Logo no início do romance, lemos:

\footnotetext{
* Universidade Federal do Rio Grande do Sul, Porto Alegre (RS), Brasil. kclucena@gmail.com
} 
$\mathrm{O}$ ar faulkneriano dessa história não podia deixar de me atrair: o jovem de futuro brilhante, recém-formado em direito, que larga tudo e desaparece; o ódio da mulher, que inventa um desfalque e o manda para a cadeia sem que ele se defenda ou se dê ao trabalho de esclarecer o engano. No fim, eu escrevera um romance com a história, usando o tom de As palmeiras selvagens, ou melhor: usando os tons que Faulkner adquire quando traduzido por Borges, com o quê, sem querer, o relato ficou parecendo uma versão mais ou menos paródica de Onetti. (2010, p. 12).

Ou seja, está presente nesse romance inicial de Piglia o assunto que ele percorreria em textos críticos posteriores, o cruzamento entre tradução e tradição, em especial no papel determinante que o Borges tradutor desempenhou na tradição argentina ${ }^{1}$. Detalharemos o tema a seguir. Há ainda uma segunda referência à tradução em Respiração artificial, já na parte final do romance:

[...] Arlt safa-se da tradição do bilinguismo; está fora disso, Arlt lê traduções. [...] Arlt é o primeiro, por outro lado, a defender a leitura de traduções. [...] Daí que o modelo de estilo literário - onde ele vai encontrar? Encontra-o onde pode ler, ou seja, nas traduções espanholas de Dostoiévski, de Andreiev. Encontra-o no estilo dos péssimos tradutores espanhóis, nas edições baratas de Tor. (2010, p. 120-121).

Novamente Piglia ficcionaliza nesse romance um problema teórico sobre o qual se debruçaria posteriormente, em especial no texto Tradición y traducción (2011), que comentaremos adiante. Essas menções à presença da tradução na definição do estilo de um escritor (Arlt) ou no tom capaz de impactar escritas locais (Onetti que parece Faulkner traduzido por Borges) deveriam conferir a Piglia um lugar destacado nos Estudos de tradução, já que fazem coro (e às vezes antecipam) à reflexão que teóricos relevantes como Itamar Even-Zohar (nascido em Tel Aviv, 1939) fixaram no campo da tradução. No entanto, é preciso considerar que Piglia não é um teórico do assunto, ele o aborda a partir de um ponto de vista quase ficcional. Por isso, é preciso relativizar expressões como "péssimos tradutores espanhóis", já que parece ser um tipo de parecer não fundamentado em avaliação estrita desses textos. De todo modo, essas "intuições" de Piglia rendem muito se cruzadas às de teóricos da tradução.

Nesse sentido, comento neste texto os estudos de Even-Zohar e Ricardo Piglia, além de mencionar rapidamente a pesquisa do italiano Franco Moretti (1950) que, salvo engano, está em diálogo com a dos críticos anteriormente citados no que diz respeito à tradução. Darei mais atenção ao argumento de Piglia, pois é o que mais se atém à literatura hispano-americana, da qual retirarei os exemplos para o segundo momento deste texto, em que apresento dois casos de escritores

1. O livro Borges y la traducción, de Sergio Waisman (Adriana Hidalgo editora, 2005), é excelente referência sobre o tema. 
que tiveram sua formação intelectual marcada pela leitura de textos traduzidos: o argentino Roberto Arlt (1900 - 1942) e o uruguaio Juan Carlos Onetti (1909 - 1994). Com esses exemplos, pretendo demonstrar que para escritores recémchegados à cultura letrada o acesso à literatura estrangeira geralmente se dá via tradução e que esse movimento não só cria disputas no campo literário, como também ilumina os critérios de inclusão ou exclusão desses autores nos panoramas literários de seus países/regiões.

\section{TRÊS ESTUDIOSOS DO PROBLEMA}

Como dito anteriormente, proponho um paralelo entre as pesquisas de Itamar Even-Zohar, Ricardo Piglia e Franco Moretti atentando para o que eles pensaram sobre a tradução e seu impacto na formação de tradições literárias locais. Faz-se necessário destacar, no entanto, diferenças importantes entre as abordagens dos três autores. Referência inevitável para os Estudos de tradução, o israelense Itamar Even-Zohar ficou conhecido especialmente pela teoria dos polissistemas, que ele começou a pensar no final dos anos 1970, com reformulações em 1990 e 2005. Trata-se, portanto, de nome central para o campo da tradução, que entende o problema a partir de um ponto de vista teórico e filosófico, o que lhe rendeu algumas críticas. Edwin Gentzler, por exemplo, afirma:

Apesar dos avanços feitos por Even-Zohar, vários problemas menores com a teoria dos polissistemas podem ser notados. O primeiro problema, que ele reconhecia, é sua tendência a propor universais baseados em parcas evidências. Uma análise mais extensa de relações textuais e culturais deve ser feita antes que os "universais" sejam apresentados de maneira convincente. As contradições em seus dados demonstram a natureza efêmera do que ele tenta $\operatorname{articular}(2009$, p. 155).

Destaco a crítica de Gentzler, menos para diminuir a relevante contribuição de Even-Zohar para os estudos literários e da tradução e mais para expor que o que talvez falte ao israelense é central na abordagem de Franco Moretti, a saber, a empiria, os dados, as estatísticas. O depoimento de Moretti em Atlas do romance europeu (1997) dá notícia do tipo de investigação que lhe interessa:

$\mathrm{O}$ "experimento" deu certo, em outras palavras, graças à abstração e à quantificação: séries amplas, consistentes, em que a importância final de uma forma era sempre maior do que a soma das partes separadas. É uma das fronteiras do trabalho crítico: o desafio da quantidade - dos 99 por cento de toda a literatura publicada que desaparece do campo da visão e que ninguém quer ressuscitar. Esse alargamento do campo literário, produzido pela lógica interna da pesquisa geográfica, pegou-me completamente de surpresa: o novo método exigia novos dados - mas aqueles dados ainda não existiam e não sabia direito como encontrá-los, e este 
livro dá apenas alguns passos na nova direção. Mas é um desafio maravilhoso, para todos os historiadores culturais (2003, p.15).

Parece haver, portanto, uma diferença metodológica importante entre EvenZohar e Moretti - este mais atento à empiria, aquele, à reflexão filosófica - mas ambos compartilham uma visão sistêmica sobre a literatura, compreendendo-a em suas intersecções com as forças sociais, históricas e econômicas. Ricardo Piglia, por outro lado, quando trata de tradução, o faz primeiramente como romancista (os excertos de Respiração artificial já citados), depois como ensaísta e conferencista. Não se trata, portanto, de trabalho de fôlego investigativo como os de Even-Zohar e Moretti, e sim de reflexão baseada em grandes intuições e na sua experiência de escritor. Guardadas essas diferenças metodológicas, ainda assim parece válido apresentar lado a lado os argumentos dos três autores sobre tradução e tradição.

Even-Zohar defende, em A posição da literatura traduzida dentro do polissistema literário (1990), que a literatura traduzida pode assumir papel central na formação de diferentes polissistemas, dependendo da força desses sistemas na literatura mundial:

Dizer que a literatura traduzida mantém uma posição central no polissistema literário é dizer que ela participa ativamente na modelagem do centro desse mesmo polissistema. Em tal situação, a literatura traduzida é, em geral, uma parte integral das forças inovadoras e está, portanto, propensa a ser identificada com eventos importantes na história literária no momento em que eles estão acontecendo. Essa situação implica que nenhuma distinção clara entre obras "originais" e "traduzidas" é mantida, e que são muitas vezes os escritores de maior prestígio (ou membros da vanguarda prestes a se tornar escritores de prestígio) que produzem as traduções mais apreciadas ou conspícuas. Ademais, em situações em que emergem novos modelos literários, a tradução é propensa a se tornar um dos meios de elaboração do novo repertório. Através das obras estrangeiras, novas características (tanto princípios como elementos), até então inexistentes, são introduzidas na literatura alvo. Essas características possivelmente incluem não apenas novos modelos de realidades para substituir uma realidade anterior e estabelecida que já não é efetiva, mas também toda uma gama de outras características, como novas linguagens (poéticas), ou técnicas e padrões composicionais. Fica claro que os próprios princípios de seleção de obras a serem traduzidas são determinados pela situação que rege o polissistema (alvo): os textos são selecionados de acordo com sua compatibilidade com as novas abordagens e o papel supostamente inovador que podem assumir dentro da literatura alvo. (2012, p. 4 -destacados meus).

O conceito de polissistema de Even-Zohar dá à tradição literária um viés dinâmico mais amplo do que a relação de autores e obras organizados cronologicamente. A literatura aparece como um campo atravessado por aspectos sociais que impactam nas formas estéticas, desnaturalizando uma visão mais 
essencialista do que seja o cânone, o estilo de época, a poética de determinado escritor. Parte importante dessa desnaturalização passa pela compreensão de que as noções de centro e periferia são definidoras do fenômeno literário e estão associadas ao lugar mais ou menos protagônico que os países/regiões ocupam na ordem mundial. Assim, a literatura produzida nos centros europeus - especialmente França e Inglaterra - ocupa posição também central no polissistema literário, ao passo que literaturas oriundas de lugares não-hegemônicos estariam em condição periférica.

Mas o interesse da teoria de Even-Zohar está na função articuladora que a literatura traduzida pode ter entre sistemas centrais e periféricos. Quanto mais central o sistema, mais ele se autoalimenta da literatura de sua própria língua; quanto mais periférico, mais presente está a literatura traduzida. E essa literatura em tradução torna-se muitas vezes um fator de novidade para o sistema que a recebe, fazendo circular técnicas, linguagens e modelos até então ausentes na literatura receptora. Even-Zohar atenta ainda para o papel que escritores de prestígio desempenham na articulação entre sistemas centrais e periféricos ao traduzirem obras canônicas introduzindo-as na literatura de chegada. A reflexão de Piglia sobre Borges, mencionada rapidamente e à qual voltaremos em breve, parece ser um exemplo iluminador da teoria de Even-Zohar.

Note-se a similaridade entre o raciocínio de Even-Zohar e esta passagem de Conjeturas sobre a literatura mundial (2000), de Franco Moretti:

[...] em culturas que integram a periferia do sistema literário (ou seja, quase todas as culturas, dentro e fora da Europa) o romance moderno desponta não como um desenvolvimento autônomo, mas como uma conciliação entre uma influência formal ocidental (em geral francesa ou inglesa) e matérias locais. (2000, p. 177).

Na sequência, Moretti abre uma nota de rodapé: "a conciliação formal é geralmente preparada por uma maciça onda de traduções da Europa ocidental" (2000, p. 174). Na mesma linha de Even-Zohar, Moretti vê a tradução como uma força capaz de engendrar novas formas em locais que as desconhecem. Moretti está pensando especificamente no romance moderno (Even-Zohar se ocupa de um recorte mais amplo de gêneros) que, para ele, se desenvolveu na conciliação entre forma estrangeira e matéria local. Vale destacar que Moretti também entende a literatura a partir da dialética centro e periferia, inscrevendo-se em uma matriz historiográfica e sociológica da crítica literária. 
Chegamos finalmente ao ensaio de Ricardo Piglia. Em Tradición y traducción ${ }^{2}$, o escritor argentino dá exemplos de momentos em que a tradução ajudou a criar a tradição. O primeiro caso é a já mencionada tradução de Jorge Luis Borges para The Wild Palms (1939) [Las palmeras salvajes] de William Faulkner, em 1940, apenas um ano depois da publicação em inglês. Segundo Piglia, esse livro de Faulkner é dos menos conhecidos do autor nos Estados Unidos, mas um dos principais na América Latina e essa alteração na hierarquia dos textos é um dos efeitos da tradução. Nas palavras de Piglia:

Fíjense -y acá tenemos un efecto de la traducción- que la novela Las palmeras salvajes es más conocida en América Latina que otras novelas como Absalón Absalón, que es considerada la gran novela de Faulkner, y que muchas otras de sus novelas, tal vez mejores para cualquier estudioso de las novelas de Faulkner en Estados Unidos. Las palmeras salvajes en el contexto norteamericano es una novela muy menor. Pero en América Latina, Las palmeras salvajes parece mejor que Absalón, Absalón, de modo que podemos decir que el canon faulkneriano ha cambiado de lugar porque la traducción ha convertido ese texto en una gran novela. Quiero decir que la traducción está produciendo, en este caso y en otros, cambios en la propia jerarquía de los textos. Es decir, aquí encontramos un ejemplo clarísimo de lo que supone trasladar un texto a otro contexto, trasladar un texto a otra tradición, donde también la jerarquía y los valores de los textos pueden modificarse (2011, p. 9 - destacados meus)

Nesse primeiro exemplo de Piglia, temos uma mostra do impacto que um escritor de prestígio (voltando à categoria de Even-Zohar) atuando como tradutor pode ter em determinada tradição. A assinatura de Borges na tradução do livro de Faulkner conferiu a esse texto uma ressonância que o colocou no topo do cânone faulkneriano em espanhol. Talvez pudéssemos pensar que os escritores hispanoamericanos que se assumem influenciados por Faulkner (García Márquez, Onetti, Benedetti e tantos outros) tenham conhecido, ao menos no início, o Faulkner de Borges, que, segundo Piglia, é estilisticamente bastante distante do original em inglês. Novamente Piglia:

En el original, la primera página de la novela de Faulkner, por ejemplo, no tiene ningún tipo de puntuación, salvo el punto aparte; es una masa. Hay alguien que está bajando por una escalera, con una lámpara, en una noche de tormenta, y nosotros no nos damos cuenta quién es el que está bajando, ni que se trata de una noche de tormenta, ni que es una lámpara, hasta que no hemos terminado de navegar por ese párrafo. Entonces, lo primero que hacemos para aclarar la situación es dividir el párrafo, poner un punto aparte. Cuando leemos la traducción de Borges, en cambio, inmediatamente entendemos lo que está pasando: es un médico a quien en medio de una noche de tormenta alguien le golpea la puerta, y él está bajando con una lámpara

2. Registro da conferência ministrada por Piglia em 17 de março de 2011, como ato de inauguração do Magíster em Literatura Comparada, Facultad de Artes Liberales, Universidad Adolfo Ibáñez, em Santiago do Chile. Algumas ideias dessa conferência apareceram no livro Las tres vanguardias: Saer, Puig, Walsh (Eterna Cadencia, 2016), reunião de onze aulas ministradas por Piglia na Universidade de Buenos Aires, em 1990. Salvo engano, o texto completo da conferência segue inédito em livro. 
para iluminar su camino. Es decir, hay una intervención borgeana sobre la escritura; borgeana, en el sentido de que es su propio estilo el que está actuando sobre otro estilo: el de Faulkner. Esto produce, desde luego, una extraordinaria traducción, porque en ella se encuentran los sabores y tonos de Faulkner con mucha mayor nitidez que en cualquier otra versión. Siento que es una traducción donde la intervención borgeana es continua. No sé si recuerdan la novela; está dividida en dos capítulos alternados: por un lado está una pasión amorosa muy intensa, una de las grandes historias de amor que se han contado; y por el otro, la historia de un preso que escapa de la prisión, se fuga, y se va en una balsa por el río con una mujer embarazada; el río ha crecido y avanzan en medio de la crecida del río. En un momento se acercan a la orilla y Borges señala: "repechó la ribera fangosa", que es una frase textual de "Las ruinas circulares". Es decir, usa un texto propio para mostrar una acción que está presente en la obra de Faulkner (2011, p. 8).

Ao identificar fragmentos de contos e o estilo do Borges escritor no tradutor do texto de Faulkner e, mais do que isso, ao valorizar essa prática como uma extraordinária tradução, Piglia desvia o foco da desgastada discussão sobre fidelidade ou infidelidade do texto traduzido em relação ao original, e lança uma perspectiva empírica que pergunta quais textos determinada cultura escolhe traduzir, quem os escolhe, quem os traduz, por que, como são recebidos, quem os lê, que impacto eles têm na criação ficcional de autores dessa cultura receptora, enfim, uma série de questionamentos que colocam a tradução no centro do debate sobre a tradição literária nacional. É claro que uma análise mais cuidadosa da tradução de Borges para The Wild Palms ${ }^{3}$ poderia relativizar o parecer de "extraordinária tradução" feito por Piglia, ainda mais se considerarmos os limites entre tradução e adaptação propostos por vertentes mais linguísticas dos Estudos de tradução. Ainda assim, esse tipo de análise que parte da tradução para entender processos de circulação de estilos, formas e ideias pode ser tão importante para o campo quanto análises mais pontuais interessadas no cotejo entre original e tradução.

Até aqui, Piglia nos apresentou a tradução alterando a hierarquia dos textos por meio de um escritor de prestígio que impõe seu estilo ao fazer tradutório. Em outro exemplo, Piglia acrescenta novo argumento: a tradução preparando a recepção de autores locais, construindo um contexto de leitura. Essa reflexão parte das traduções de Borges para a literatura policial (Stevenson, Wells, Chesterton, Kipling):

Para seguir con Borges, podríamos dar un ejemplo de lo que significa la construcción de un contexto en su caso: a partir de los años treinta, Borges realiza un trabajo de traducción muy sistemático para poner en circulación una serie de textos - básicamente del género policial, a los cuales él estaba ligado y cierto tipo de literatura considerada "menor" en ese momento:

3. Patricia Willson é autora de análise extremamente cuidadosa não só das traduções de Borges, também das de outros escritores vinculados à revista argentina Sur, em La constelación del Sur: traductores y traducciones en la literatura argentina del siglo XX (Siglo XXI editores Argentina, 2004). 
Stevenson, Wells, Chesterton, Kipling, que habían sido los best sellers de su época, cuando Borges tenía quince o dieciséis años. En estos escritores, Borges encontró un tipo de relación entre la aventura, la investigación y la reflexión, que era muy útil para el tipo de literatura que él quería escribir. Él estaba esperando que esos textos ayudaran a crear un espacio para sus relatos. No quería que se los conectara con Thomas Mann o Herman Hesse, que eran los escritores que estaban de moda en la década del cuarenta; ésa era la gran literatura. Si uno pone a Borges al lado de Thomas Mann, no queda nada de Borges (2011, p. 11 - destacados meus).

Assim, de acordo com a interpretação de Piglia, os livros policiais traduzidos por Borges preparariam a recepção dos contos que ele escreveria em seguida e que estavam distantes da "moda" literária. Quando os hispânicos recebessem os textos de Borges, teriam como compará-los às traduções da literatura policial anglófona e, deste paralelo, a escrita de Borges sairia esteticamente vencedora, o que talvez não tivesse acontecido caso a única comparação possível fosse com A montanha mágica ou $\mathrm{O}$ lobo da estepe. A argumentação de Piglia parece levar a um calculismo que não sei se estava no horizonte de Borges. Talvez a afirmação de Piglia seja até um tanto leviana ou denote algo não raro entre os escritores argentinos posteriores a Borges: a necessidade de "matar o pai". De todo modo, a ideia de que a tradução constrói um contexto, cria um espaço que depois será preenchido por autores da tradição local está, salvo engano, em consonância com os pontos de vista de Even-Zohar e Moretti apresentados anteriormente. A tradução seria, então, uma etapa fundamental da formação de sistemas literários locais.

Um terceiro exemplo, ainda de Piglia. O próprio Piglia, no final dos anos 1960, dirigiu a coleção Serie Negra, que traduzia romances policiais norte-americanos (Chandler, Hammer). Como Borges, Piglia quer "construir um contexto", mas neste caso para tratar de política de forma não evidente, trazer novas fórmulas para a literatura engajada, comprometida, e a literatura policial que traduz serve para sugerir saídas estéticas que, segundo ele, não estavam disponíveis na tradição local:

De esta forma, insisto, la traducción funciona como la construcción de contextos. Yo mismo recuerdo que dirigí una colección policial de literatura norteamericana que comenzó en 1968 y que se llamó "Serie Negra". Nosotros hacíamos esa serie con la intención de cuestionar lo que hasta ese momento se consideraba literatura social, literatura política, porque en muchos sentidos pensaba que la literatura policial era un modo de poner en juego ciertas cuestiones ligadas a lo que podríamos llamar la crítica social, que estaban hechas con un sistema narrativo muy distinto, sin que el contenido fuera inmediatamente político. El tipo de relación entre corrupción, dinero o poder, que circulaba en las novelas de Hammer o de Chandler nos ayudaba a los escritores de América Latina a evitar una tendencia a la literatura comprometida, a la literatura social, que persistía. El género policial nos ayudó a pensar que había una manera de hablar de la realidad que no fuera siempre tan evidente, tan directa, y que más bien trabajara 
con ciertos núcleos secretos, o con ciertos elementos ocultos. Entonces yo traducía a esos escritores porque los admiraba mucho, pero también era un modo de intervenir en el debate que en ese momento era muy tenso, sobre cuáles eran las poéticas a partir de las cuales un escritor podía hacerse cargo de los conflictos de su época. La idea era que para hacerse cargo de un momento o de una realidad no había que escribir exclusivamente novelas realistas, clásicas, sino que también se podía escribir textos donde aparecieran investigaciones y tensiones en torno a cuestiones como el dinero, el poder, las conspiraciones. En fin, todo lo que funciona en el género policial (2011, p. 12-13 - destacados meus).

Tentei demonstrar que a exemplificação de Ricardo Piglia de alguma forma elucida as questões teóricas propostas por Itamar Even-Zohar e Franco Moretti no que diz respeito ao contato entre tradução e tradição literária. Agora gostaria de propor um novo paralelo: tradução e distinção, algo na linha do comentário de Piglia sobre Arlt no trecho de Respiração artificial citado no início deste texto. Estamos ainda na esteira de compreensão da literatura em suas relações com o processo histórico-social, em especial nas possibilidades negadas ou permitidas a escritores de diferentes origens sociais.

\section{DOIS ESCRITORES FORMADOS PELO PROBLEMA}

O argentino Roberto Arlt (1900-1942) e o uruguaio Juan Carlos Onetti (1909-1994), escritores não pertencentes à elite cultural de seus países, de classe média baixa, de origem imigrante, foram fortemente marcados pela tradução. $\mathrm{Na}$ verdade, sua formação intelectual dependeu da leitura de textos traduzidos bem mais do que dependeram da tradução os escritores da elite criolla (Borges, Oliverio Girondo, Victoria Ocampo, embora entre eles haja diferentes graus de erudição), proprietários de bibliotecas pessoais multilíngues pelas quais trafegavam com desenvoltura, ou pelo menos com mais desenvoltura do que os escritores recémchegados à cultura letrada.

Beatriz Sarlo tratou do problema em Modernidade periférica (1988):

[as revistas] Claridad e Los Pensadores propõem um discurso baseado em traduções que tem como resultado a democratização, pela difusão massiva, da cultura europeia progressista no contexto rio-platense. As polêmicas e os enfrentamentos estão nas revistas: desde o conflito, realizado das mais diversas maneiras, entre intelectuais de origem tradicional e intelectuais recém-chegados, de origem imigrante, até o debate sobre o lugar da arte e da cultura na sociedade, sua relação, afirmativa ou negativa, com os gostos do público e a funcionalidade ou não funcionalidade da arte em relação às ideologias e à política. [...] Conflitos sociais espalham seu fantasma sobre os debates culturais e estéticos. A questão da língua (quem fala e escreve um castelhano aceitável); das traduções (quem está autorizado e por quais motivos a traduzir) [...]. (2010, p. 55 - destacados meus). 
$\mathrm{Na}$ Buenos Aires e na Montevidéu ${ }^{4}$ do início do século XX, traduzir pode ser uma distinção social: os autores que traduziam de um lado (Borges) e os que liam traduções de outro (Arlt, Onetti). Arlt e Onetti quando falam de si ora assumem uma postura de exibição da cultura, o alarde de leituras de literatura estrangeira (em tradução), ora de exibição da incultura, o ressentimento com a precariedade de sua formação. Ao comentar a biografia de Roberto Arlt, Sarlo conclui:

Todas as autobiografias expõem, às vezes de maneira sarcástica, a privação cultural que forma parte do passado exibido. Elas misturam dois temas, a precariedade de sua formação e a exibição de leituras, que são contraditórios, mas, de alguma forma, complementares, porque a exibição de leituras ocupa o lugar que outros títulos não podem outorgar, nem por linhagem nem por aquisição. O sarcasmo é uma das formas do ressentimento em face da distribuição desigual da cultura (2010, p. 96).

O famoso prólogo a Los Lanzallamas (1931) é uma mostra da exibição de incultura: "soy el desposeído, el que viene de afuera, el que no lee lenguas extranjeras, el que no tiene tiempo para hacer estilo" (ARLT, 2000, p. 285). Já em uma Aguafuerte porteña de 1929, Arlt exibe sua cultura. Dirigindo-se ao leitor: "Se você não leu O sonbo de Makar, de Vladimiro Korolenko, trate de ler. O assunto é este..." (2013, p. 75). Parece óbvio, mas é preciso dizer: tanto Arlt como os leitores que resolvessem seguir sua dica de leitura o fariam pelo texto traduzido. Nesse sentido, tanto ao assumir a postura ressentida sobre sua formação intelectual, quanto ao colocar-se como figura autorizada a sugerir leituras, a tradução é um problema central para Arlt.

Vale lembrar que as Aguafuertes de Arlt eram publicadas no jornal popular El Mundo, criado em 1928 para atender a um novo público leitor: os imigrantes que desde o final do século XIX desembarcavam aos milhares no porto de Buenos Aires para trabalhar na construção da cosmopolita capital. A família Arlt chega à Argentina nesse fluxo, e o escritor vai aproveitar o boom editorial das primeiras décadas do século 20 e transformar-se no escritor que provavelmente melhor registrou a cidade em transformação e aquele que se comunicou com as classes populares. As dicas de leitura de Arlt respondem a esse contexto. Não a vanguarda francófona e anglófona que circulava na elitizada revista Sur, e sim a periférica literatura russa lida em tradução, e que a partir de então passa a também figurar na tradição argentina.

Aplicando o raciocínio de Ricardo Piglia ao caso de Roberto Arlt, a seleção de literatura russa feita por este e os pareceres que emite em suas Aguafuertes

4. Beatriz Sarlo apresenta, em Modernidade periférica: Buenos Aires 1920 e 1930, somente o panorama cultural relativo à capital argentina. No entanto, pode-se perceber que algo semelhante, embora em menores proporções, acontecia em Montevidéu, como demonstra Pablo Rocca em Revistas culturales del Río de la Plata (Ediciones de la Banda Oriental, 2009). 
ampliam a tradição literária argentina e incluem nela autores antes ausentes. E que Arlt leia esses autores em tradução tem influência em seu estilo como romancista. São comuns os comentários sobre a escrita dostoievskiana de Roberto Arlt; não são tão comuns as referências aos tradutores do escritor russo para a língua espanhola que possibilitaram o contato de Arlt com esse autor.

Observar a trajetória intelectual de Juan Carlos Onetti também nos ajuda a compreender o paralelo entre tradução e distinção. No caso de Juan Carlos Onetti está igualmente presente a exibição de cultura/incultura. Um registro precioso dessa dialética são as cartas que Onetti trocou com o crítico argentino Julio Payró, entre 1937 e 1955, organizadas em livro por Hugo Verani (2009). Há uma diferença importante de posição no campo letrado entre Payró e Onetti. Diz Verani: "Payró fue un reconocido intelectual, académico, profesor, crítico de arte y viajero, de sólida formación humanística, situado en las antípodas de Onetti, el sedentario escritor, autodidacta y anti-intelectual, que nunca terminó la secundaria" (2009, p. 11). Sendo assim, as declarações de Onetti nessa correspondência buscam a aprovação do crítico e registram a expectativa de que este lhe facilite o ingresso no circuito literário portenho ${ }^{5}$. Em uma carta de 1938:

Estoy releyendo a Dostoiewsky y cosas sobre él. De aquí surge una "comparanza", tan tonta y tan lejos de tocar la verdad como una Ramonada, pero que repite en otra zona, casi correctamente, una sensación mía. Va: parece que la gente de Montevideo - ésa con la que uno se tropieza, se enlaza y hace líos - hubiera leído, también, a don Fedor. De aquí una gran comprensión, tolerancia, falta de sorpresa para lo inesperado. Pero, entre todos han preferido al Príncipe idiota. En cambio, la gente de Baires - aquella con la que uno tropieza y etc. - prefiere a los personajes "activos" del ruso, los "endemoniados". De aquí, una riqueza de líos y un terreno más generoso para nos [sic], los epatadores amateurs (2009, p. 65-66).

Onetti não só lê Dostoievski (em tradução) como utiliza o escritor para interpretar comportamentos dos habitantes de Buenos Aires e Montevidéu, o montevideano lamentando-se do provincianismo de sua cidade em comparação à cosmopolita capital argentina. Além disso, essa é uma clara exibição da cultura de Onetti frente a um interlocutor mais intelectualizado e visto como oportunidade de ascensão no campo literário.

Outra carta de Onetti, também de 1938. Nessa fica evidente o papel da tradução em sua formação cultural: "Tengo Santuario, en francés, de Faulkner. Recién empecé a leerlo, muy interesante y difícil" (2009, p. 71). Várias perguntas surgem a partir dessa afirmação: era mais fácil para Onetti entender o livro em francês (edição de 1933) do que em inglês (edição original de 1931), dada a proximidade

5. Escrevi sobre o tema em outro texto: Cartas de Juan Carlos Onetti para Julio Payró, disponível em < http:// revistaseletronicas.pucrs.br/ojs/index.php/fale/article/view/15347/11367>. 
entre espanhol e francês? Era mais difícil ter acesso à edição em inglês? E essa dificuldade que sente Onetti, é pela língua ou pelo texto hermético de Faulkner? Independentemente das respostas que se dê a essas perguntas, o tema da literatura traduzida está presente na relação de Onetti com autores estrangeiros.

E um último comentário de Onetti, em carta de 1941: "Leí Viejo muere el cisne y discrepo con usted sobre sus méritos" (2009, p. 112). A tradução para o espanhol, a cargo de R. Crespo y Crespo, desse livro de Huxley, After many a summer dies the swan (1939), saiu no mesmo ano da carta de Onetti, 1941, pela Editorial Losada, de Buenos Aires. Mais um indício do leitor de traduções que foi Onetti.

Por fim, se nas primeiras décadas do século XX, ler traduções estigmatizava esses autores recém-chegados à cultura letrada, distantes que estavam dos autores da elite que podiam ler literatura estrangeira no original e muitas vezes a traduziam para o espanhol, hoje, e em muito graças a leituras como as de Even-Zohar, Piglia e Moretti, conseguimos constatar o relevante papel da literatura traduzida na formação intelectual desses autores e, a partir das marcas que as leituras em tradução deixaram em suas obras, a função da literatura traduzida na formação de sistemas literários locais. Sempre que um escritor hispano-americano for identificado como dostoievskiano ou faulkneriano seria importante considerar que um tradutor participou dessa identificação. Vale destacar também que com o estabelecimento da tradução como área acadêmica, tem diminuído o estigma com a leitura em tradução, embora ler no original ainda confira prestígio e distinção (às vezes, pedantismo).

Com este texto quis demonstrar dois movimentos: o primeiro, de cunho mais teórico, que põe lado a lado Itamar Even-Zohar, Franco Moretti e Ricardo Piglia como autores que concordam na identificação da literatura traduzida como potência formadora de tradições literárias locais; já o segundo, de caráter mais aplicado, expõe novamente a potência da literatura traduzida, mas nesse caso na formação intelectual de autores recém-chegados ao campo letrado, evidenciando o paralelo entre tradução e distinção social. Reconheço o tanto de esquematismo que pode haver nas conclusões apresentadas aqui. Como comentado, Even-Zohar, Moretti e Piglia são autores de perspectivas metodológicas bastantes diferentes; colocá-los lado a lado incide em algum risco que, quero acreditar, vale a pena ser corrido para iluminar um problema esboçado pelos três. Do mesmo modo, associar tradução e formação intelectual de escritores que vieram "de baixo" pode gerar alguma ressalva, já que escritores de elite também se formam na leitura de traduções. Ainda assim, me parece defensável que o que para uns é imposição de classe, para outros pode ser limitação temporária de acesso. 


\section{REFERÊNCIAS BIBLIOGRÁFICAS}

ARLT, R. (1928-1930) Águas-fortes portenhas seguidas de Águas-fortes cariocas. Trad. Maria Paula Gurgel Ribeiro. São Paulo: Iluminuras, 2013.

ARLT, R. (1929/1931) Los siete locos/Los lanzallamas. Edición crítica Mario Goloboff. Colección Archivos. Scipione Cultural, 2000.

EVEN-ZOHAR, I. (1990). A posição da literatura traduzida dentro do polissistema literário. Trad. Leandro de Ávila Braga. Revista Translatio, n. 3, 2012. Disponível em: < http://seer. ufrgs.br/index.php/translatio/article/view/34674/22321>. Acesso em: 7 fev. 2018.

EVEN-ZOHAR, I. (1990). Polysystem Studies. Poetics Today: International Journal for Theory and Analysis of Literature and Communication. v. 11, n. 1. Disponível em: < http:// www.tau.ac.il/ itamarez/works/books/ez-pss1990.pdf>. Acesso em: 7 fev. 2018.

GENTZLER, E. (2001). Teorias contemporâneas da tradução. Trad. Marcos Malvezzi. São Paulo: Madras, 2009.

LUCENA, K. C. (2014). Cartas de Juan Carlos Onetti para Julio Payró. Revista Letras de Hoje. PUCRS. Porto Alegre, v. 49, n. 2. Disponível em: < http://revistaseletronicas.pucrs. br/ojs/index.php/fale/article/view/15347/11367>. Acesso em: 7 fev. 2018.

MORETTI, F. (1997) Atlas do romance europeu: 1800-1900. Trad. Sandra Guardini Vasconcelos. São Paulo: Boitempo, 2003.

MORETTI, F. (2000). Conjeturas sobre a literatura mundial. Trad. José Marcos Macedo. Novos Estudos CEBRAP. n. 58, nov. 2000.

ONETTI, J. C. (1937-1955). Cartas de un joven escritor: Correspondencia con Julio E. Payró. Edición crítica, estudio preliminar y notas de Hugo Verani. Rosario: Beatriz Viterbo Editora; Buenos Aires: TrilceLom, 2009.

PIGLIA, R. (1980). Respiração artificial. Trad. Heloisa Jahn. São Paulo: Companhia das Letras, 2010.

PIGLIA, R. (2016). Las tres vanguardias: Saer, Puig, Walsh. Buenos Aires: Eterna Cadencia.

PIGLIA, R. (2011). Tradición y traducción. Santiago do Chile. Disponível em: < http:// www.uai.cl/images/sitio/facultades_carreras/esc_artes_liberales/master/literatura comparada/TradiciontraduccionRicardoPiglia.pdf $>$. Acesso em: 7 fev. 2018. 
ROCCA, P. (2009). Revistas culturales del Río de la Plata: Campo literario: debates, documentos, índices (1942 - 1964). Montevideo: Banda Oriental.

SARLO, B. (1988) Modernidade periférica: Buenos Aires 1920 e 1930. Trad. Júlio Pimentel Pinto. São Paulo: Cosacnaify, 2010.

WAISMAN, S. (2005). Borges y la traducción. Trad. Marcelo Cohen. Buenos Aires: Adriana Hidalgo, 2005.

WILLSON, P. (2004). La constelación del Sur: traductores y traducciones en la literatura argentina del siglo XX. Buenos Aires: Siglo XXI Argentina.

Recebido: 12/02/2018

Aceito: 25/02/2018 